\title{
Supporting Information: Correlating processing conditions to short- and long-range order in coating and drying lithium-ion batteries
}

Renee M. Saraka, Samantha L. Morelly, Maureen H. Tang, Nicolas J. Alvarez*

Department of Chemical and Biological Engineering, Drexel University, Philadelphia, PA, 19026 USA

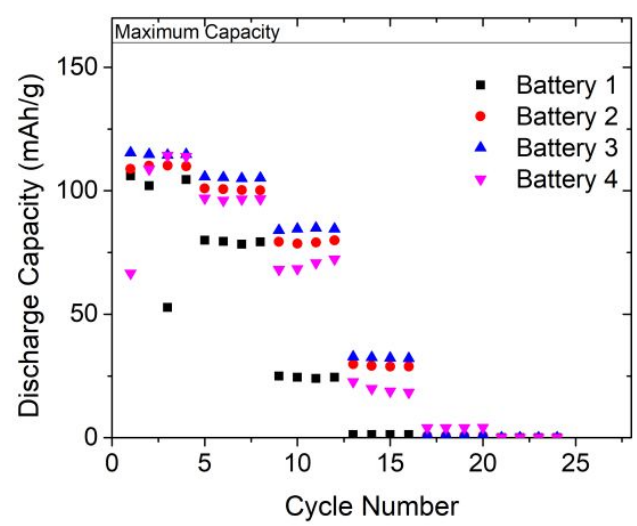

Figure S1: Four cycles at each $\mathrm{C}$ rate were measured for each battery made and tested. An average of 3-4 batteries per electrode film were created and tested. 


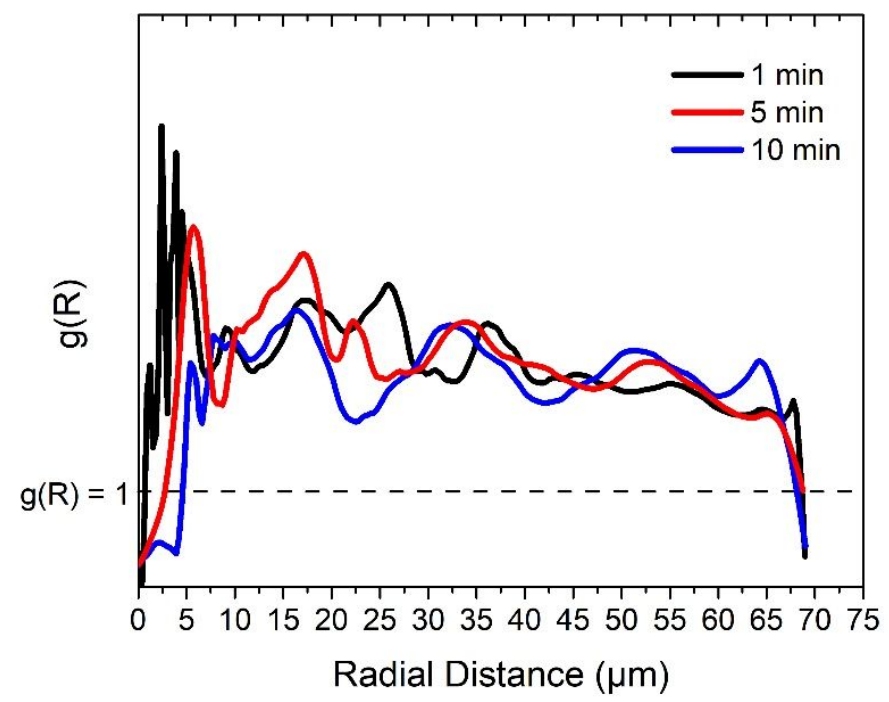

Figure S2: To ensure that the thresholding technique used eliminates dependence on EDS collection time, $\mathrm{Mn} / \mathrm{C}$ radial distribution functions were calculated from EDS images collected over 1, 5 and 10 minutes. All elemental maps show very similar peak distributions and locations, indicating that the analysis method is robust and does not depend on the sampling methods.

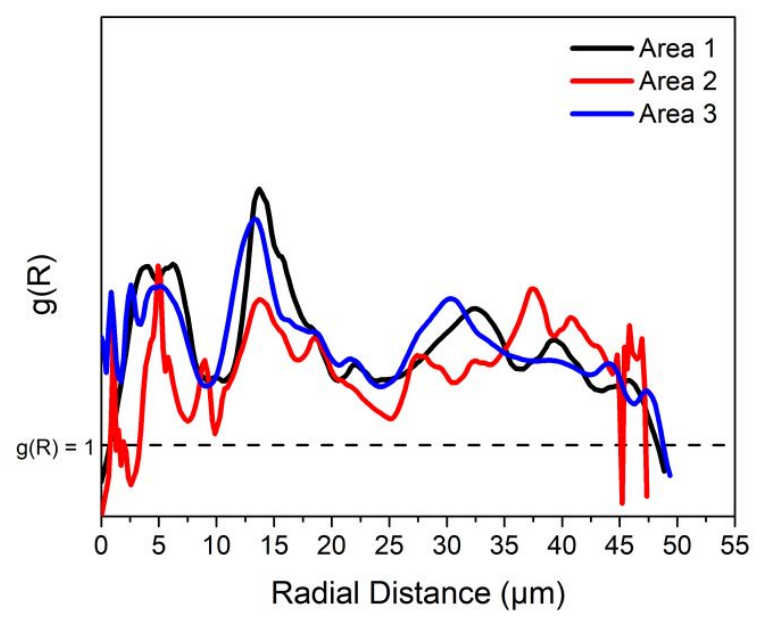

Figure S3: To ensure that the analysis technique was robust and did not depend on a given region of an electrode film, three $\mathrm{C} / \mathrm{Mn}$ radial distribution functions were determined from EDS elemental maps of $\mathrm{C}$ and $\mathrm{Mn}$ collected at three distinct regions of an electrode cross-section. The results show that the radial distribution functions are very similar for the three different spatial regions. This important result indicates that a single EDS image is sufficient to characterize the connectivity of $\mathrm{C}$ and $\mathrm{Mn}$ and that the method and analysis technique is indeed robust and representative of a given electrode cross-section. These radial distribution functions represent the electrode processed at $300 \mathrm{~s}^{-1}$, and $150{ }^{\circ} \mathrm{C}$ (i.e. a discharge capacity of $140 \mathrm{mAh} / \mathrm{g}$ at $0.5 \mathrm{C}$ ). 

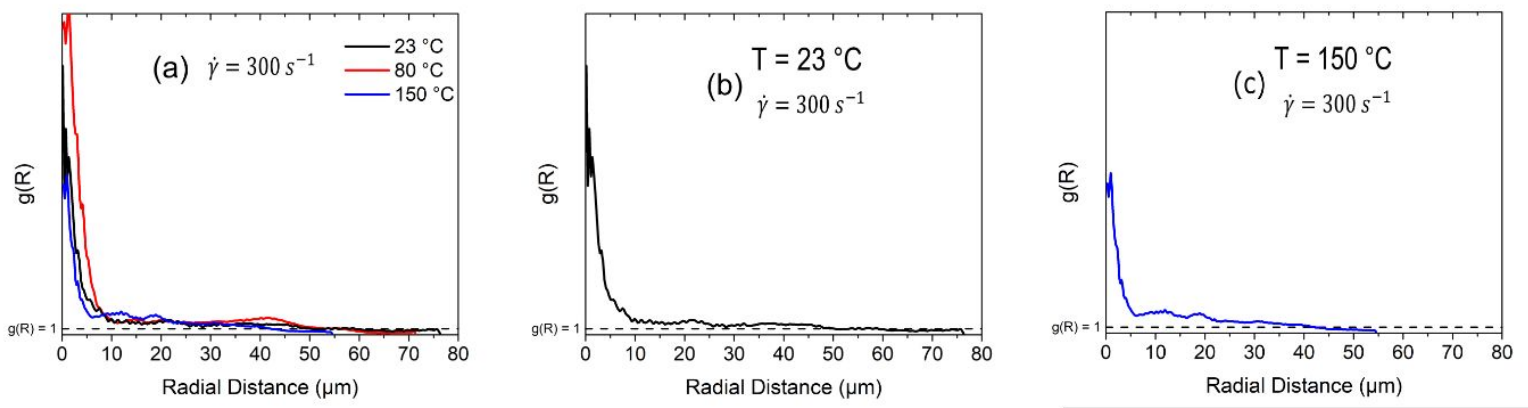

Figure S4: $\mathrm{C} / \mathrm{C}$ coordination in $300 \mathrm{~s}^{-1}$ electrodes for (a) all three tried temperatures $(23,80$ and $150{ }^{\circ} \mathrm{C}$ ), (b) $23{ }^{\circ} \mathrm{C}$ shows one large peak between $0-10 \mu \mathrm{m}$, but remains flat suggesting random order throughout the electrode (c) $150^{\circ} \mathrm{C}$ has a much higher discharge capacity, yet exhibits a similar singular peak at short range with no coordination at higher radial distances.



Figure S5: Small amplitude oscillatory shear frequency sweep of the initial slurry structure without any applied shear indicates a strong gel is created. 

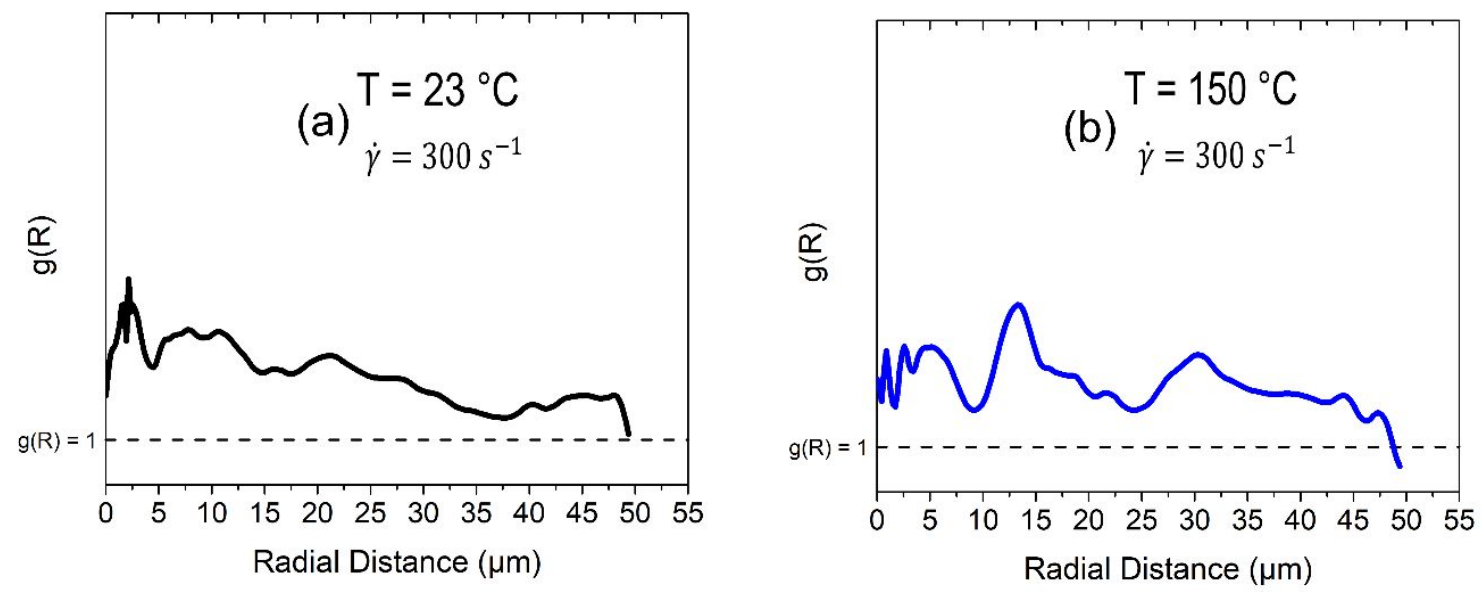

Figure S6: Mn/C coordination for $300 \mathrm{~s}^{-1}$ electrodes dried at (a) $23{ }^{\circ} \mathrm{C}$ and (b) $150{ }^{\circ} \mathrm{C}$ show that with increasing temperature, the short- and long- range order measured immediately after shear is maintained, as shown in (b), but with extended drying time, the structure changes in accordance with Figure 5a, as suggested by the lack of order in (a).

Corresponding Author:

*Nicolas J. Alvarez - nja49@drexel.edu 